\title{
Development and Validation of a Questionnaire for the Assessment of Pelvic Floor Disorders and Their Risk Factors During Pregnancy and Post Partum
}

\author{
Entwicklung und Validierung eines Fragebogens \\ für Beckenbodenfunktionsstörungen und deren Risikofaktoren \\ während der Schwangerschaft und postpartal
}

\author{
Authors \\ Melanie Metz ${ }^{1}$, Bärbel Junginger ${ }^{1}$, Wolfgang Henrich ${ }^{2}$, Kaven Baeßler ${ }^{1}$ \\ Affiliations \\ 1 Beckenbodenzentrum Charité, Klinik für Gynäkologie CBF, Berlin, \\ Germany \\ 2 Klinik für Geburtsmedizin CVK und CCM, Berlin, Germany \\ Key words \\ pelvic floor dysfunction/disorders, pregnancy, post partum, \\ questionnaire \\ Schlüsselwörter \\ Beckenbodenfunktionsstörungen, Schwangerschaft, postpartal, \\ Fragebogen \\ $\begin{array}{ll}\text { received } & 1.12 .2016 \\ \text { revised } & 29.1 .2017 \\ \text { accepted } & 30.1 .2017\end{array}$ \\ Bibliography \\ DOI http://dx.doi.org/10.1055/s-0043-102693 \\ Geburtsh Frauenheilk 2017; 77: 358-365 @ Georg Thieme Verlag KG \\ Stuttgart · New York | ISSN 0016-5751 \\ Correspondence \\ PD Dr. med. Kaven Baeßler, Leiterin Beckenboden-Zentrum \\ Beckenbodenzentrum Charité, Klinik für Gynäkologie CBF \\ Hindenburgdamm 30, 12203 Berlin, Germany \\ kaven.baessler@charite.de \\ $\theta$ \\ Deutsche Version unter: \\ http://dx.doi.org/10.1055/s-0043-102693 \\ Supporting Information: \\ http://dx.doi.org/10.1055/s-0043-102693
}

\section{ABSTRACT}

Introduction The aim of this study was to develop and validate a questionnaire for the assessment of pelvic floor disorders, their symptoms and risk factors in pregnancy and after birth including symptom course, severity and impact on quality of life.

Methods The validated German pelvic floor questionnaire was modified and a new risk factor domain developed. The questionnaire was initially completed by 233 nulliparous women in the third trimester of pregnancy and at six weeks $(n=148)$ and one year $(n=120)$ post partum. Full pyschometric testing was performed. The clinical course of symptoms and the influence of risk factors were analysed.
Results Study participants had a median age of 31 (19-46) years. 63\% had spontaneous vaginal deliveries, $15 \%$ operative vaginal deliveries and $22 \%$ were delivered by caesarean section. Content validity: Missing answers never exceeded $4 \%$. Construct validity: The questionnaire distinguished significantly between women who reported bothersome symptoms and those who did not. Reliability: Cronbach's alpha values exceeded 0.7 for bladder, bowel and support function, and 0.65 for sexual function. The test-retest analysis showed moderate to almost complete concordance. The intraclass coefficients for domain scores (between 0.732 and 0.818 ) were in acceptable to optimal range. Reactivity: The questionnaire was able to track changes significantly with good effect size for each domain. Risk factors for pelvic floor symptoms included familial predisposition, maternal age over 35 years, BMI above 25, nicotine abuse, subjective inability to voluntarily contract the pelvic floor musculature and postpartum wound pain.

Conclusion This pelvic floor questionnaire proved to be valid, reliable and reactive for the assessment of pelvic floor disorders, their risk factors, incidence and impact on quality of life during pregnancy and post partum. The questionnaire can be utilised to assess the course of symptoms and treatment effects using a scoring system.

\section{ZUSAMMENFASSUNG}

Einleitung Ziel der Arbeit war es, einen Beckenbodenfragebogen zu entwickeln und zu validieren, der Risikofaktoren und Symptome von Beckenbodenfunktionsstörungen in der Schwangerschaft und nach der Geburt, ihre Beeinflussung der Lebensqualität, den Schweregrad und den Symptomverlauf erfasst.

Methoden Der validierte Deutsche Beckenbodenfragebogen wurde angepasst, eine Risikofaktoren-Domäne entwickelt und von initial 233 nulliparen Frauen im letzten Trimenon, 6 Wochen $(n=148)$ und 1 Jahr postpartal $(n=120)$ beantwortet und vollständig psychometrisch getestet. Symptomverläufe und Einfluss von Risikofaktoren wurden ausgewertet.

Ergebnisse Die Frauen waren im Median 31 (19-46) Jahre alt. Spontan vaginal wurden $63 \%$, vaginal operativ $15 \%$ und per sectionem $22 \%$ entbunden. Inhaltsvalidität: Fehlende Antworten überstiegen nie 4\%. Konstruktvalidität: Der Fragebogen unterschied signifikant zwischen Frauen mit und ohne Leidensdruck. Reliabilität: Die Cronbachs-AlphaWerte lagen über 0,7 für die Blasen-, Darm und Haltefunktion, für die Sexualfunktion bei 0,65. Die Test-Retest-Analyse zeigte moderate bis fast vollkommene Übereinstimmung. Die Intraclass-Koeffizienten für die Domänenscores lagen zwischen 0,732 und 0,818 im akzeptablen bis optimalen Bereich. Reaktivität: Der Fragebogen konnte Veränderungen signifikant verfolgen mit guten Effektgrößen für alle Domänen. Risikofaktoren für Beckenbodensymptome waren die familiäre 
Prädisposition, ein maternales Alter ab 35 Lebensjahre, ein BMI ab 25, Nikotinabusus, die subjektive Unfähigkeit, den Beckenboden willentlich zu kontrahieren und der postpartale Wundschmerz.

Schlussfolgerung Es konnte ein valider, zuverlässiger und reaktiver Beckenbodenfragebogen für die Erfassung von Risikofaktoren und Be- ckenbodendysfunktionen, deren Häufigkeit und Beeinflussung der Lebensqualität in der Schwangerschaft und postpartal entwickelt werden. Durch ein Scoringsystem ist es möglich, den Fragebogen zur Beurteilung eines Symptom- bzw. Therapieverlaufs einzusetzen.

\section{Introduction}

Pelvic floor disorders such as urinary incontinence and genital prolapse often initially have little impact on quality of life and are temporarily tolerated, being regarded as normal for a particular phase of life e.g. during pregnancy and the immediate postpartum period. If they persist or progress, however, they can affect women's hygiene and social well-being significantly [1-3]. Despite the generally high prevalence of urinary incontinence and genital prolapse $[4,5]$ counselling on pelvic floor function is mostly not part of routine practice in the German health system. Pregnancy, childbirth and the immediate postpartum period, where the demands on the pelvic floor and the incidence of pelvic floor trauma are particularly high, would offer an opportunity for such counselling.

In Germany no systematic analysis of pelvic floor symptoms and possible predisposing factors in pregnancy and postpartum has been published to date. An analysis of this kind would require a validated assessment tool that is able to measure what it was intended to measure in a reliable and valid fashion and that is able to differentiate between different patient or control groups [6]. According to the recommendations of the International Consultation on Incontinence (ICI) [6] psychometric testing of a questionnaire includes testing its reliability, validity and reactivity.

Validated pelvic floor questionnaires allow the assessment of pelvic floor symptoms, their frequency and severity, their course over time and how they impact on quality of life $[3,4]$. The aim of this study was to design and validate a novel pelvic floor questionnaire specifically for pregnancy and the postpartum period. A further aim was to develop a risk domain for the assessment of risk factors for pelvic floor disorders in pregnancy and peri-/postpartum. Since emotional appraisal of the birth experience and postnatal depression may influence patient answers $[7,8]$ the questionnaire also covered these aspects.

\section{Methods}

\section{Questionnaire design}

The questionnaire was based on the validated German language version of the Australian Pelvic Floor Questionnaire [9-11] with four domains of pelvic floor function: bladder, bowel, support and sexual function. Additional domains for risk factors and the course of childbirth were entirely newly developed. The childbirth domain, which was completed by study participants as an extra module 6 weeks post partum, included questions on the course of the delivery, emotional appraisal of the birth and associated postpartum pain.
In order to adapt the questionnaire to younger women questions on manual reduction of prolapse for micturition and defecation were removed. Questions on soiling, as an addition to anal incontinence questions, as well as questions on awareness of bladder and rectum filling were newly included as were questions on the impact on quality of life, degree of incontinence (amount) and the duration of symptoms. The layout was optimised to improve general clarity and interpretability.

\section{Validity}

In order to test content validity explorative interviews were conducted with midwives, urogynaecologists and physiotherapists to assess questionnaire design and question formulation. Women from the fields of communication science and psychology without urogynaecological training were also interviewed. During a pretest the questionnaire was repeatedly adapted to meet the language and cognitive requirements of interviewed women. The upper limit for missing answers was set at $4 \%$ per question since higher percentages imply incomprehensible questions [12].

Construct validity was tested to ensure that the questionnaire can significantly discriminate between women with and without pelvic floor symptoms [12]. Here the domain scores for women with and without significant subjective suffering were compared and tested for the differentiating change of 1 score point ("minimal important difference"), a value previously confirmed in validation studies [11]. Bothersomeness was analysed with respect to bladder, bowel, prolapse and sexual symptoms using the question: "How much do your bladder/bowel/prolapse/sexual symptoms bother you?" and the following choice of answers: "Not applicable - I do not have symptoms", "not at all”, "a little”, "quite a lot" and "very much". The answer "a little" was already regarded as bothersomeness and the variable dichotomised accordingly.

\section{Reliability}

The reliability of results on the basis of symptom severity rather than measurement error was tested using internal consistency and a test-retest analysis. The internal consistency - the strength of association of individual factors in each domain to one another - was tested using Cronbach's alpha [12,13].

The test-retest reliability to determine the questionnaire's reproducibility was conducted in the 3rd trimester as part of the pretesting. In view of the rapid physical changes that occur during pregnancy a much shorter interval to repeat questioning was applied in contrast to the recommended interval of two weeks [12, 14]. The degree of concordance/agreement was measured with Cohen's kappa [15]. In addition, the absolute agreement between the test-retest results of different individuals was tested with the intraclass correlation coefficient (ICC) $[16,17]$. 


\section{Reactivity "sensitivity to change"}

"Distribution-based" methods were used to test the questionnaire's sensitivity to changes following the birth and one year postpartum. For this, effect size (mean raw score change/standard deviation of baseline score) and standardized response mean (mean raw score change/standard deviation of change) were calculated $[13,18]$.

\section{Study participants and questionnaire implementation}

Recruitment occurred from antenatal clinics and antenatal classes in Berlin. Included were nulliparous pregnant women aged 18 years and over, with as yet uncomplicated pregnancy. Insufficient German language proficiency, diabetes mellitus, neurological disorders, fetal anomalies and other diseases with the potential to adversely affect questionnaire validation compliance were exclusion criteria. The calculation of power and sample size were based on the effect size estimated at validation of the "German pelvic floor questionnaire". With a power of $80 \%$ and $\alpha=0.05$ a score change of 1 in a domain (minimal important clinical difference) can be significantly detected from a sample size of $n=50$ [11].

- Fig. 1 provides a graphic representation of the study flow including questionnaire development, pretesting, included women and missing data. Study participants completed the questionnaire initially in the third trimester of pregnancy, then at 6 weeks and one year post partum; for the latter, participants received the questionnaire by e mail. Questionnaire distribution and all interviews were undertaken by the lead author (MM).

\section{Risk factors and comorbidity}

The clinical course of pelvic floor symptoms, comorbidity and the influences of risk factors were analysed with the Mann-Whitney $U$ test, cross-tables, a binary logistic regression and a multivariate regression for independence.

\section{Results}

233 women in the 3rd trimester of pregnancy were initially recruited. Median age was 31 (19-46) years. 148/233 (64\%) were available for interview at 6 weeks post partum. Of the 148, 63\% $(94 / 148)$ had a spontaneous vaginal delivery, $15 \%$ (22/148) an operative vaginal delivery and $22 \%(32 / 148)$ a caesarean section. $120 / 148$ (62\%) women completed the questionnaire at one year postpartum online or by mail. Overall 109 women completed the questionnaire at all three scheduled time points. - Fig. 1 shows the study course. Most women who dropped out could either not be contacted or did not complete the questionnaire. There was no significant difference in reported pelvic floor symptoms (first questionnaire) between women who continued to participate and those who dropped out (prevalence of urinary incontinence 46 vs. $51 \%$, anal incontinence 24 and $24 \%$, prolapse symptoms 30 vs. $21 \%$, sexual dysfunction 69 vs. $64 \%$ ), nor was there a difference in median age (31 years) or BMI (26 vs. $27 \mathrm{~kg} / \mathrm{m}^{2}$ in the third trimester).

- Fig. 2 summarises the prevalence of selected typical pelvic floor symptoms in the four domains over the course of the study. $49 \%$ of women reported urinary incontinence in the third trimes-

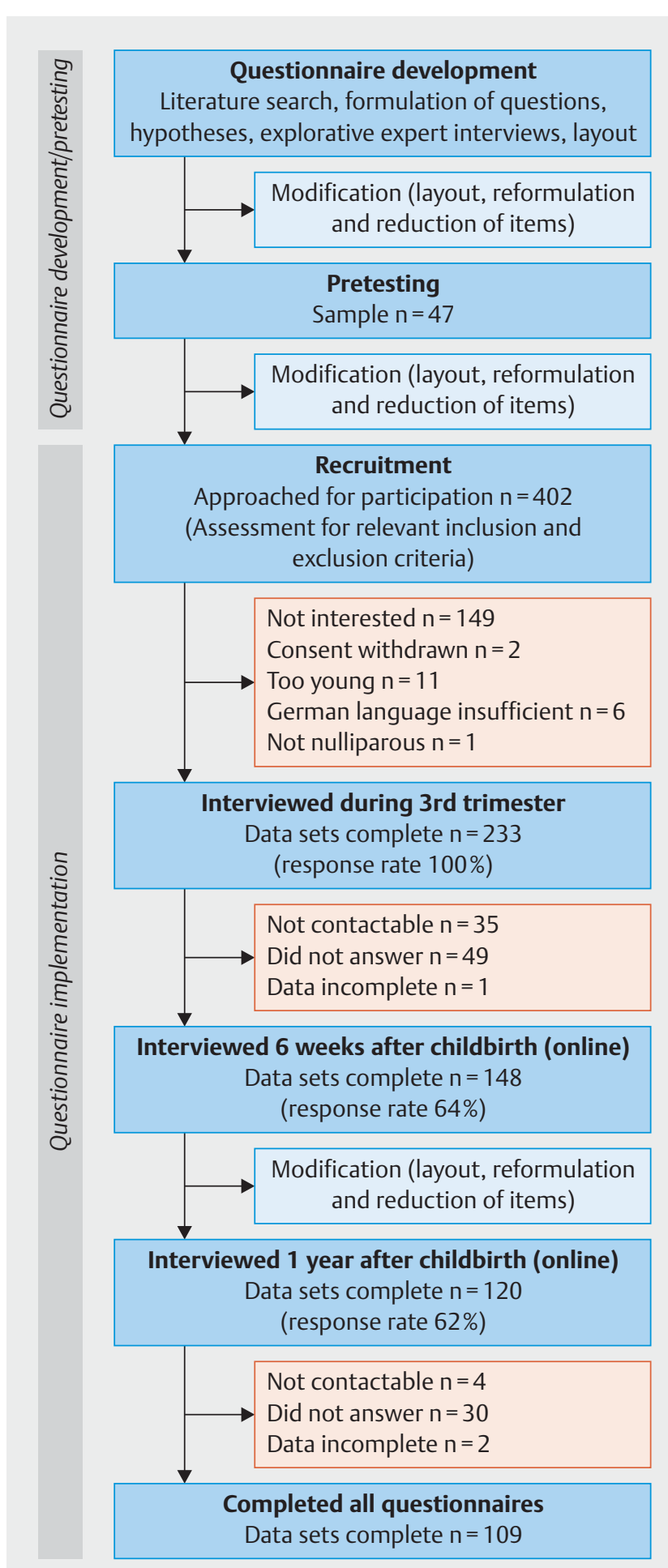

- Fig. 1 Study process and recruitment.

ter, mainly stress incontinence or mixed incontinence (45\%). Urinary incontinence in general declined to $36 \%$ in the immediate postpartum period due to resolution of stress incontinence. More than half of women had no urinary incontinence at one year postpartum. 


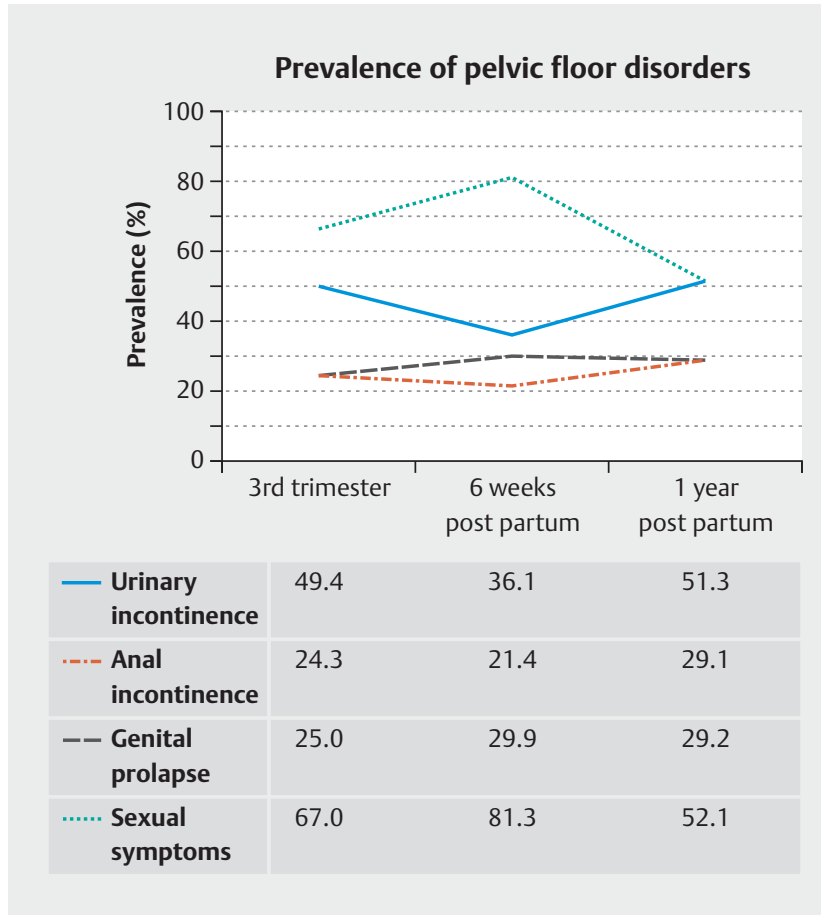

- Fig. 2 Prevalence (\%) of pelvic floor disorders at the different interview time points.

\section{Internal consistency reliability}

Cronbach's alpha values for the domains of the pelvic floor questionnaire were in a good to very good range ( $\bullet$ Table 1 ). Since values for Cronbach's alpha can be low when there are fewer than 10 items in a domain, averages for inter-item correlation were calculated in addition to assess homogeneity in the sexual function domain. At 0.24 and 0.20 for the interview time points during pregnancy and post partum, the values are considered "very good" (from 0.2 to 0.4 ) [6]. Cronbach's alpha for the childbirth domain was 0.64 with an inter-item correlation average for fewer than 10 items of 0.29 .

\section{Test-retest reliability}

Testing of the questionnaire's measurement stability was undertaken in the pretest phase with 47 women who had completed the questionnaire in the third trimester of pregnancy. > Table 2 shows Cohen's kappa values as an agreement coefficient and the ICC with 95\% confidence intervals indicating the lowest and highest values of the respective items, as absolute agreement and as an overall value for each functional domain. Values were between 0.43 (moderate agreement) and 0.96 (almost complete agreement). In the bladder domain the ICC was between 0.709 and 0.951 , in the bowel domain between 0.797 and 0.982 , in the pelvic support domain between 0.658 and 0.883 and in the sexual domain from 0.644 to 0.793 , all in an acceptable range.

\section{Construct validity}

The questionnaire discriminated significantly $(p<0.05)$ between women with and without bothersome symptoms, both pre- and postpartum ( $\vee$ Table 3 ). For women who reported little to great bother in the four pelvic floor domains, the symptom scores for bladder, bowel and prolapse domains were one score point significantly higher than women without bothersomeness, which corresponds to the previously established minimal important difference [11].

- Table 1 Internal consistency reliability. Cronbach's alpha values of the different pelvic floor domains for pregnancy and postpartum questionnaires.

\begin{tabular}{|l|l|l|l|l|l|}
\hline & Bladder function & Bowel function & Pelvic support & Sexual function & Childbirth \\
\hline 3rd trimester & 0.78 & 0.79 & 0.77 & 0.65 & - \\
\hline 6 weeks postpartum & 0.77 & 0.60 & 0.72 & 0.61 & 0.64 \\
\hline
\end{tabular}

- Table 2 Test-retest reliability. Cohen's kappa values and intraclass correlation coefficient (ICC) with 95\% confidence intervals (CI).

\begin{tabular}{|l|l|l|l|}
\hline Domain/question & $\begin{array}{l}\text { Kappa } \\
\text { Individual questions }\end{array}$ & $\begin{array}{l}\text { ICC (95\% Cl) } \\
\text { Domain scores }\end{array}$ & P \\
\hline Bladder function & $0.43-0.85$ & $0.818(0.709-0.951)$ & $<0.001$ \\
\hline Bowel function & $0.50-0.96$ & $0.874(0.797-0.982)$ & $<0.001$ \\
\hline Pelvic support & $0.49-0.70$ & $0.801(0.658-0.883)$ & $<0.001$ \\
\hline Sexual function & $0.47-0.64$ & $0.732(0.644-0.793)$ & $<0.001$ \\
\hline Familial predisposition & 0.88 & - & $<0.001$ \\
\hline Nicotine & 0.70 & - & $<0.001$ \\
\hline Pelvic floor contraction & 0.67 & - & $<0.001$ \\
\hline Perineal pain & 0.80 & - & $<0.001$ \\
\hline
\end{tabular}


- Table 3 Construct validity. Symptom-score difference (Mann-Whitney U test) between women with and without subjective suffering.

\begin{tabular}{|c|c|c|c|c|c|}
\hline & & $\begin{array}{l}\text { Bothersome- } \\
\text { ness }\end{array}$ & n & $\begin{array}{l}\text { Score points } \\
\text { Median (range) }\end{array}$ & $\mathbf{p}$ \\
\hline \multirow[t]{4}{*}{ Bladder function } & 3rd trimester & No & 160 & $1.5(0.0-4.4)$ & $<0.001$ \\
\hline & & Yes & 72 & $2.5(0.6-6.4)$ & \\
\hline & Post partum & No & 129 & $0.8(0.0-3.3)$ & $<0.001$ \\
\hline & & Yes & 16 & $1.9(0.8-5.0)$ & \\
\hline \multirow[t]{4}{*}{ Bowel function } & 3rd trimester & No & 171 & $1.7(0.0-4.4)$ & $<0.001$ \\
\hline & & Yes & 60 & $2.8(1.7-5.0)$ & \\
\hline & Post partum & No & 113 & $1.7(0.6-3.9)$ & 0.037 \\
\hline & & Yes & 34 & $2.2(0.6-5.0)$ & \\
\hline \multirow[t]{4}{*}{ Pelvic support } & 3rd trimester & No & 210 & $0.0(0.0-5.0)$ & $<0.001$ \\
\hline & & Yes & 22 & $3.3(0.0-6.7)$ & \\
\hline & Post partum & No & 118 & $0.0(0.0-5.0)$ & $<0.001$ \\
\hline & & Yes & 22 & $3.3(1.7-6.7)$ & \\
\hline \multirow[t]{4}{*}{ Sexual function } & 3rd trimester & No & 105 & $0.7(0.0-4.3)$ & 0.045 \\
\hline & & Yes & 29 & $1.4(0.7-4.3)$ & \\
\hline & Post partum & No & 70 & $0.0(0.0-3.6)$ & $<0.001$ \\
\hline & & Yes & 24 & $1.4(0.7-3.6)$ & \\
\hline
\end{tabular}

- Table 4 Reactivity. Domain scores, effect size and standardised response mean ( \pm standard deviation) showing changes at the different interview time points pregnancy (preg.), 6 weeks ( $6 \mathrm{w} \mathrm{pp}$ ) post partum and 1 year (1 a pp) post partum; (t-test for paired samples; $\mathrm{T}=$ time point).

\begin{tabular}{|c|c|c|c|c|c|c|}
\hline Domain scores & Mean score T1 & Mean score T2 & $\begin{array}{l}\text { Mean score } \\
\text { change }\end{array}$ & $\begin{array}{l}\text { Effect } \\
\text { size }\end{array}$ & $\begin{array}{l}\text { Standardised } \\
\text { response mean }\end{array}$ & $\mathbf{p}$ \\
\hline Bladder-preg. - 6 w pp & $2.02 \pm 1.1$ & $0.93 \pm 0.84$ & $-1.09 \pm 0.31$ & 1.00 & 1.14 & 0.000 \\
\hline Bladder - 6 w pp- 1 a pp & $0.93 \pm 0.84$ & $1.07 \pm 0.80$ & $0.14 \pm 0.68$ & 0.16 & 0.21 & 0.072 \\
\hline Bowel-preg. $-6 w p p$ & $2.03 \pm 0.98$ & $1.98 \pm 1.06$ & $-0.06 \pm 1.06$ & 0.06 & 0.05 & 0.624 \\
\hline Bowel- 6 w pp - 1 a pp & $1.98 \pm 1.06$ & $1.58 \pm 1.05$ & $-0.39 \pm 0.90$ & 0.44 & 0.43 & 0.000 \\
\hline Prolapse - preg. - 6 w pp & $0.44 \pm 1.02$ & $0.76 \pm 1.31$ & $0.32 \pm 1.54$ & 0.30 & 0.23 & 0.023 \\
\hline Prolapse - 6 w pp - 1 a pp & $0.76 \pm 1.31$ & $0.86 \pm 1.41$ & $0.10 \pm 1.42$ & 0.07 & 0.07 & 0.482 \\
\hline Sex-preg. $-6 w p p$ & $0.94 \pm 1.0$ & $1.53 \pm 1.1$ & $0.59 \pm 1.36$ & 0.58 & 0.42 & 0.001 \\
\hline Sex-6wpp-1app & $1.53 \pm 1.1$ & $0.84 \pm 0.97$ & $-0.69 \pm 1.17$ & 0.60 & 0.59 & 0.000 \\
\hline
\end{tabular}

\section{Content validity}

The rate of missing answers did not exceed $4 \%$ for any of the questions in the final questionnaire.

\section{Reactivity and scoring system}

- Table 4 shows the means of the domain scores and score changes, the effect size and standardised response mean. The questionnaire was found to be reactive to changes during pregnancy and the postpartum period, especially for bladder function, with statistically significant score changes $(p<0.01)$.

\section{Risk factors}

In the univariate analysis familial predisposition, age over 35 years, BMI over 25 , nicotine abuse and subjective inability to voluntarily contract the pelvic floor muscles at various interview time points were identified as risk factors. During pregnancy, participating in sports activities more than three times a week was found to be a protective factor against anal incontinence. Backache, lifting heavy objects, sitting for long periods and chronic cough were not confirmed as risk factors.

Obstetric parameters such as mode of delivery, birth-related trauma, episiotomy, perineal sutures, wound pain, birth weight, breastfeeding and participation in postnatal classes were analysed for association with pelvic floor disorders. The risk of developing urinary incontinence 6 weeks after a vaginal birth was threefold higher than after caesarean section (OR 2.7 [1.0-7.1]); at one year post partum however the risk was no longer increased. The risk of prolapse symptoms after vaginal birth increased from OR $5.1(1.1-23.2)$ at six weeks postpartum to OR $8.2(1.9-36.2)$ at 
- Table 5 Significant relevant risk factors for pelvic floor disorders: Odds ratios in the multivariate analysis $(\mathrm{OR}=$ odds ratio, $95 \% \mathrm{Cl}$; PFC = pelvic floor contraction).

\begin{tabular}{|c|c|c|c|c|c|}
\hline & Interview time point & Risk factors & $\begin{array}{l}\text { Regression } \\
\text { coefficient B }\end{array}$ & $\mathbf{p}$ & OR (Cl) \\
\hline \multirow[t]{6}{*}{ Urinary incontinence } & 3rd trimester & PFC inability & 1.554 & 0.032 & $4.7(1.1-19.6)$ \\
\hline & & Fam. predisposition & 0.748 & 0.049 & $2.1(1.0-4.5)$ \\
\hline & & BMI 25+ & 0.671 & 0.022 & $2.0(1.1-3.5)$ \\
\hline & 6 weeks post partum & BMI 25+ & 1.111 & 0.008 & $3.0(1.3-6.9)$ \\
\hline & 1 year post partum & Fam. predisposition & 1.207 & 0.036 & $3.3(1.1-10.3)$ \\
\hline & & Age $35+$ & 1.323 & 0.022 & $3.8(1.2-11.6)$ \\
\hline \multirow[t]{5}{*}{ Anal incontinence } & 3rd trimester & PFC inability & 1.554 & 0.022 & $4.7(1.2-18.0)$ \\
\hline & & Fam. predisposition & 0.865 & 0.026 & $2.4(1.1-5.1)$ \\
\hline & & Sport $>3 \times /$ week & -0.685 & 0.040 & $0.5(0.3-1.0)$ \\
\hline & 1 year post partum & Age $35+$ & 1.029 & 0.020 & $2.8(1,2-6,6)$ \\
\hline & & PFC inability & 1.125 & 0.015 & $3.1(1.2-7.6)$ \\
\hline \multirow[t]{2}{*}{ Prolapse } & 6 weeks post partum & Nicotine abuse & 0.719 & 0.049 & $2.1(1.0-4.2)$ \\
\hline & 1 year post partum & Fam. predisposition & 1.181 & 0.016 & $3.3(1.3-8.5)$ \\
\hline \multirow[t]{2}{*}{ Sexual dysfunction } & 3rd trimester & PFC inability & 0.920 & 0.012 & $2.5(1.2-5.1)$ \\
\hline & & Nicotine abuse & 0.951 & 0.008 & $2.6(1.3-5.2)$ \\
\hline
\end{tabular}

one year. Results of the multivariate logistic regression are summarised in $>$ Table 5 .

\section{Discussion}

We have demonstrated that the self-administered pelvic floor questionnaire, which was modified especially for women during pregnancy and the postpartum period, is reliable, valid and reactive. The questionnaire developed here is an adapted version of the German pelvic floor questionnaire, which has previously been validated in urogynaecological patients $[9,11]$. The German pelvic floor questionnaire was chosen since it is self-administered and, using 42 questions with separate scales, covers all domains of pelvic floor dysfunction including bladder, bowel, pelvic support and sexual function and also assesses symptom severity, incidence and the impact on quality of life. There are no other validated questionnaires in the German language covering all areas of pelvic dysfunction or that have been psychometrically tested for pregnancy and childbirth. A search of the international literature did not reveal any tools specifically developed for women in pregnancy and the postpartum period - though a number of validated questionnaires for the assessment of urinary or anal incontinence, prolapse symptoms or sexual dysfunction are available.

The internal consistency - i.e. the strength of association of individual factors in each domain to one another - was determined using Cronbach's alpha. Values were acceptable to very good. For the domains sexual function and childbirth the average of interitem correlation was also calculated since Cronbach's alpha values can be low when number of items are less than 10 . Inter-item correlation was between 0.20 and 0.29 , which is within the optimal range of $0.2-0.4$. The overall Cronbach's alpha value for the ques- tionnaire was 0.69 , which is in the range of recommendable survey tools $[12,13]$. The risk factor domains were not analysed since an association between the very different factors (voluntary pelvic floor contraction, familial predisposition, nicotine abuse) was not expected. Also, reliability testing was not performed for the objective risk factors BMI and age.

When a questionnaire is used in a longitudinal study the stability of the survey tool is a significant factor. Insufficient stability can result in misinterpretation of symptom fluctuation due to progress and remission, symptom severity and frequency. Due to a strong expected influence of pregnancy and childbirth the short-term test-retest reliability was tested at an interview interval of one day rather than 14 days. Agreement coefficients for the test-retest survey were between 0.43-0.96, indicating moderate to almost complete concordance. Intraclass correlation coefficients for the domain scores were over 0.7 , in the range "acceptable to excellent".

Construct validity was confirmed by significant differences between domain symptom scores for women with and without bothersome symptoms: Among women who reported bothersomeness, the symptom score for bladder function was 1.0-1.1 points (pregnancy and post partum) significantly higher than for women who did not report bothersomeness, for bowel function 0.5 to 1.1 , for pelvic support 3.3 and for sexual function 0.7 to 1.4 points higher. These score differences correspond to the minimal important differences for the individual domains [11]. The assessment of bothersomeness appears to be a good approach to detect women in need of treatment rather than achieving a certain symptom score.

Construct validity and internal consistency of the questionnaire were calculated only at six weeks post partum and not at 1 year although the questionnaire was designed for use also at 
three or twelve months post partum. Which questionnaire should be used thereafter, the questionnaire validated for community women or the one for urogynaecological patients, remains open for discussion.

We did not test convergent validity as there is no German questionnaire available for comparison. Convergent validity was demonstrated for the German pelvic floor questionnaire for urogynaecological patients showing that pelvic floor symptoms were associated with the clinical evaluation of prolapse according to IUGA/ICS standards, as well as with stress test and urodynamic results [9].

A response rate of over $96 \%$ for the questions confirms content validity. In addition there was prior symptom identification, testing of the questionnaire as a construct and sound item formulation by means of expert interviews.

The questionnaire's reactivity (sensitivity to changes) was shown in all domains from the 3rd trimester interview compared to all further interview time points ( 6 weeks and 1 year post partum). The prospectively recorded longitudinal data on pelvic floor symptoms show a clinical course resembling the course of symptoms in international studies [19-21]. Score changes were most marked for bladder function due to both a high incidence in pregnancy and symptom resolution post partum. The non-participation rate was relatively high ( $25 \%$ six weeks and $38 \%$ one year post partum), though such rates are not uncommon for questionnaire surveys [22,23]. An analysis of demographic data and pelvic floor symptoms at the initial interview during pregnancy revealed no significant differences between women who continued to participate and those who did not. This could be seen as a weakness of the study, although the questionnaire's actual validity is not dependant on this factor.

Risk factors that have been established for postmenopausal women also showed significant association with the occurrence of pelvic floor disorders in pregnancy and post partum. These include familial predisposition, age over 35 years at childbirth, BMI of 25 and over and nicotine abuse. In addition, the subjective inability to voluntarily contract the pelvic floor muscles was also associated with pelvic floor problems. Participation in sport more than three times per week was found to be a protective factor. These factors are partly modifiable, and herein lies the importance of the risk module: Women can receive targeted counselling concerning their increased risk, and should they be overweight, smokers, or be unable to voluntarily tighten their pelvic floor muscles, appropriate measures can be taken. Although women are responsible for their own lifestyles, gynaecologists should prescribe specific pelvic floor rehabilitation when appropriate. Interestingly, vaginal birth only increased the risk of urinary incontinence at the 6 weeks postpartum interview and not at one year.

No birth-related parameters were identified as risk factors in our study collective apart from postpartum wound pain, whose meaning in our setting is unclear. It would seem that one year after childbirth it is rather the emotional appraisal of the perinatal pain experienced that is reflected.

The relatively homogenous study population is a strength of this study, however it can also be regarded as a weakness, since only primiparous women completed the questionnaire. Primiparae were chosen in order to document symptom changes and possible risk factors. The postpartum module of the final questionnaire does however address previous births, making it applicable to all women. A further strength of the study is that the whole study collective was interviewed by one person, meaning that differences in questioning technique e.g. during initial questionnaire development did not play a role.

Although only 50 women were required for reliability testing significantly more women were recruited since a further aim of the study was the identification of risk factors, and a high dropout rate was taken into account.

\section{Conclusion}

A validated questionnaire is now available for documenting the risk factors and symptoms of pelvic floor disorders, their incidence, severity and impact on quality of life during pregnancy and in the postpartum period. The scoring system allows progress evaluation. The influence of risk factors is analysed and summarised in a newly developed risk domain.

\section{Conflict of Interest}

The authors declare that no conflicts of interest exist with regard to this manuscript. The questionnaire validation was part of a DFG supported study to evaluate pelvic floor disorders.

\section{References}

[1] Hunskaar S, Lose G, Sykes D et al. The prevalence of urinary incontinence in women in four European countries. BJU Int 2004; 93: 324-330

[2] Teleman P, Lidfeldt J, Nerbrand C et al. Lower urinary tract symptoms in middle-aged women-prevalence and attitude towards mild urinary incontinence: a community-based population study. Acta Obstet Gynecol Scand 2005; 84: 1108-1112

[3] Tennstedt SL, Fitzgerald MP, Nager CW et al. Quality of life in women with stress urinary incontinence. Int Urogynecol J Pelvic Floor Dysfunct 2007; 18: 543-549

[4] Rortveit G, Daltveit AK, Hannestad YS et al. Urinary incontinence after vaginal delivery or cesarean section. N Engl J Med 2003; 348: 900-907

[5] MacLennan AH, Taylor AW, Wilson $\mathrm{DH}$ et al. The prevalence of pelvic floor disorders and their relationship to gender, age, parity and mode of delivery. BJOG 2000; 107: 1460-1470

[6] Avery KN, Bosch JL, Gotoh M et al. Questionnaires to assess urinary and anal incontinence: review and recommendations. J Urol 2007; 177: 3949

[7] Soderquist J, Wijma B, Thorbert G et al. Risk factors in pregnancy for post-traumatic stress and depression after childbirth. BJOG 2009; 116: 672-680

[8] Laursen M, Johansen C, Hedegaard M. Fear of childbirth and risk for birth complications in nulliparous women in the Danish National Birth Cohort. BJOG 2009; 116: 1350-1355

[9] Baessler K, Kempkensteffen C. [Validation of a comprehensive pelvic floor questionnaire for the hospital, private practice and research]. Gynakol Geburtshilfliche Rundsch 2009; 49: 299-307

[10] Baessler K, O’Neill SM, Maher CF et al. A validated self-administered female pelvic floor questionnaire. Int Urogynecol J 2010; 21: 163-172 
[11] Baessler K, Junginger B. [Validation of a pelvic floor questionnaire with improvement and satisfaction scales to assess symptom severity, bothersomeness and quality of life before and after pelvic floor therapy]. Aktuelle Urol 2011; 42: 316-322

[12] Revicki DA, Osoba D, Fairclough D et al. Recommendations on health-related quality of life research to support labeling and promotional claims in the United States. Qual Life Res 2000; 9: 887-900

[13] Kazis LE, Anderson J], Meenan RF. Effect sizes for interpreting changes in health status. Med Care 1989; 27: S178-S189

[14] Guyatt GH, Osoba D, Wu AW et al. Methods to explain the clinical significance of health status measures. Mayo Clin Proc 2002; 77: 371-383

[15] Koch GG, Landis JR, Freeman JL et al. A general methodology for the analysis of experiments with repeated measurement of categorical data. Biometrics 1977; 33: 133-158

[16] Shrout PE, Fleiss JL. Intraclass correlations: uses in assessing rater reliability. Psychol Bull 1979; 86: 420-428

[17] Landis JR, Koch GG. The measurement of observer agreement for categorical data. Biometrics 1977; 33: 159-174
[18] Katz JN, Larson MG, Phillips CB et al. Comparative measurement sensitivity of short and longer health status instruments. Med Care 1992; 30 : 917-925

[19] Thom DH, Rortveit G. Prevalence of postpartum urinary incontinence: a systematic review. Acta Obstet Gynecol Scand 2010; 89: 1511-1522

[20] Svare JA, Hansen BB, Lose G. Prevalence of anal incontinence during pregnancy and 1 year after delivery in a cohort of primiparous women and a control group of nulliparous women. Acta Obstet Gynecol Scand 2016; 95: 920-925

[21] Hansen BB, Svare J, Viktrup L et al. Urinary incontinence during pregnancy and 1 year after delivery in primiparous women compared with a control group of nulliparous women. Neurourol Urodyn 2012; 31: 475480

[22] MacArthur C, Glazener CM, Wilson PD et al. Obstetric practice and faecal incontinence three months after delivery. BJOG 2001; 108: 678-683

[23] Wilson PD, Herbison RM, Herbison GP. Obstetric practice and the prevalence of urinary incontinence three months after delivery. $\mathrm{Br}$ J Obstet $\mathrm{Gy}$ naecol 1996; 103: 154-161 